\title{
La especuloscopía en camilla sin estribos fue más satisfactoria para las mujeres
}

\section{Objetivo}

Analizar si un método estandarizado de posición de las piernas sin los estribos en el examen del ginecológico de rutina reduce la incomodidad física y el sentido de vulnerabilidad, y si aumenta el sentido de dominio del cuerpo en las mujeres.

Diseño

Ensayo clínico aleatorizado.

Lugar

Pacientes ambulatorias de un centro de medicina familiar de EE.UU.

\section{Participantes}

Participaron 197 mujeres adultas que concurrieron por un examen ginecológico de rutina. Se incluyeron aquellas de 18 años o mayores, y se excluyeron las que estaban embarazadas, las que presentaban alguna molestia vaginal y las que no dieron consentimiento.

\section{Intervención}

A las mujeres del grupo control se les practicó el examen ginecológico con sus talones puestos en los estribos de metal y con las piernas en un ángulo de $30-45^{\circ}$. A las pacientes del grupo intervención se las examinó con sus pies puestos en las esquinas de una camilla totalmente desplegada. A todas las mujeres se las cubrió con una sábana de tamaño estandarizado de manera que permitiera ver el periné al máximo. Se usaron espéculos de plástico y una fuente de luz externa para todos los exámenes.

\section{Medición de los resultados principales}

Puntos finales primarios: nivel de incomodidad física, sentido de vulnerabilidad y de pérdida del dominio del cuerpo, percibidos por las mujeres durante el examen ginecológico. Para tal fin, se utilizó una escala analógica visual $(0-100)^{\star}$ administrada por un observador ciego. Los puntos finales secundarios fueron la calidad de la muestra y la presencia o ausencia de células endocervicales, según el informe de anatomía patológica. Los responsables del examen ginecológico fueron ocho personas entrenadas del centro de medicina familiar: cinco médicos de planta, dos médicos residentes y un practicante de enfermería familiar (cinco hombres y tres mujeres). Todos fueron entrenados en como acomodar y cubrir a las mujeres en la camilla ginecológica. El entrenamiento fue individual, combinado con fotografías y un video.

\section{Resultados}

El estudio mostró una reducción en el sentido de vulnerabilidad en las mujeres que se les realizó el examen ginecológico sin estribo respecto al grupo control con una media que pasó de 23,6 a 13,1 (IC 95\% de la diferencia -16,6 a -4,4). También se demostró reducción del sentido de incomodidad física, aunque no hubo diferencias en cuanto al sentido de la pérdida de control (Ver tabla 1).

Tabla 1: resultados principales medidos a través de la escala analógica visual en 197 mujeres

\begin{tabular}{|c|c|c|c|}
\hline & $\begin{array}{l}\text { Sin estribos } \\
\text { Media (DS) }\end{array}$ & $\begin{array}{l}\text { Con estribos } \\
\text { Medila (DS) }\end{array}$ & Differencia (IC 95\%) \\
\hline Sentido de vulnerabilidad & $13.1(16.3)$ & $23.6(25.8)$ & $-10.5(-16.6$ a -4.4$)$ \\
\hline Disconfort fissico & $17.2(17.8)$ & $30.4(26.8)$ & $-13.2(-19.7$ a -6.8$)$ \\
\hline Sentido de pérdida de control & $17.7(23.8)$ & $23.1(27.1)$ & $-5.4(-12.6$ a 1.8$)$ \\
\hline
\end{tabular}

No hubo diferencia significativa en la calidad de la muestra entre los dos grupos. Sólo dos muestras fueron inadecuadas para la evaluación en el grupo intervención $(p=0,16)$. Dieciséis muestras de las mujeres examinadas sin los estribos y 15 de las mujeres examinadas con los estribos no tenían células endocervicales ( $p=$ $0,84)$

\section{Conclusiones}

Este estudio demuestra que las mujeres debieran poder realizar los exámenes ginecológicos de rutina sin usar los estribos para reducir la tensión que causa la incomodidad física y el hecho de sentirse vulnerable.

Fuente financiamiento: Uniformed Services Academy of Family Physicians. EE.UU.

\section{Comentario}

Cualquier estrategia que reduzca la tensión física y psicológica en las mujeres durante el examen ginecológico debería promover e incentivar un cambio en dicha práctica, dado que el cáncer de cuello de útero sigue siendo una patología frecuente y en algunos casos no diagnosticada a tiempo. Aunque este trabajo muestra que el examen sin los estribos no afectaría la suficiencia de la muestra, sería necesario un estudio más grande (de mayor tamaño muestral) para confirmar tal observación.

Este estudio constituye un aporte interesante para aquellas mujeres que con la práctica habitual del examen ginecológico se sienten incómodas y muy expuestas o vulnerables, durante el acto médico. En una investigación sobre barreras para el rastreo de cáncer de cuello uterino en la Ciudad de Buenos Aires recientemente publicado, las mujeres hicieron mención a la exposición del cuerpo, a la intromisión en la intimidad y a la falta de privacidad durante el examen ginecológico, entre otras barreras ${ }^{1}$. Resultado que coincide con otros estudios publicados y que de alguna manera están justificando la necesidad de replantear la forma de realizar el examen ginecológico ${ }^{2,3,4}$

\section{Conclusiones del comentado}

La realización de la especuloscopía sin estribos fue más satisfactoria para las pacientes. De confirmarse que esto no afecta la calidad de la muestra del Pap, podría difundirse ampliamente, y permitir la mejora de la calidad incluso en ámbitos donde se carece de camillas "ginecológicas".

* ver glosario

Nanci Giraudo [Médica de Familia. Hospital Italiano de Buenos Aires. ]

Giraudo N. La especuloscopía en camilla sin estribos fue más satisfactoria para las mujeres. Evid. actual. práct. ambul. 9(6);174.Nov-Dic 2006 . Comentado de Improving women's experience during speculum examinations at routine gynaecological visits: randomised clinical trial. Seehusen DA, Johnson DR, Earwood JS, et. al. BMJ 2006; 333: 171-173. PMID: 16803941

\section{Referencias}

1. Giraudo N, Discaciatti V, Bakalar K, Basualdo N y Dreyer C. Barreras para el rastreo de cáncer de cuello uterino en la Ciudad de Buenos Aires. Archivos de Medicina Familiar y General 2006. Vol 3 N² pp 7-21.

2. Klassen D. Preference for the no-stirrup method. Can Fam Physician 2002;48: 457

3. Larsen M, Oldeide CC, Malterud K. Not so bad after all...women's experiences of pelvic examinations. Fam Pract 1997; 14: 148-52.

4. Wright D, Fenwick J, Stephenson P, Monterosso L. Speculum `self-insertion': a pilot study. Women's Health 2005; $14: 1098$.

174 EVIDENCIA - Actualización en la Práctica Ambulatoria - Noviembre/Diciembre 2006 - Disponible en internet: www.evidencia.org 